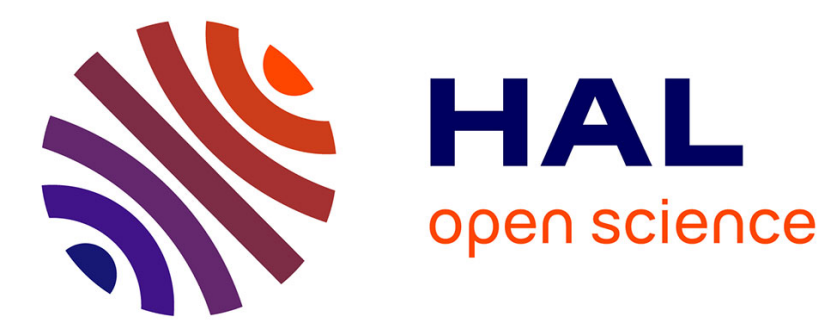

\title{
Textured Growth of Strontium Ferrite Thin Films by Sputtering
}

\author{
B. Ramamurthy Acharya, S. Prasad, N. Venkataramani, S. Shringi
}

\section{To cite this version:}

B. Ramamurthy Acharya, S. Prasad, N. Venkataramani, S. Shringi. Textured Growth of Strontium Ferrite Thin Films by Sputtering. Journal de Physique IV Proceedings, 1997, 07 (C1), pp.C1-471-C1474. 10.1051/jp4:19971191. jpa-00254841

\section{HAL Id: jpa-00254841 https://hal.science/jpa-00254841}

Submitted on 1 Jan 1997

HAL is a multi-disciplinary open access archive for the deposit and dissemination of scientific research documents, whether they are published or not. The documents may come from teaching and research institutions in France or abroad, or from public or private research centers.
L'archive ouverte pluridisciplinaire HAL, est destinée au dépôt et à la diffusion de documents scientifiques de niveau recherche, publiés ou non, émanant des établissements d'enseignement et de recherche français ou étrangers, des laboratoires publics ou privés. 


\title{
Textured Growth of Strontium Ferrite Thin Films by Sputtering
}

\author{
B. Ramamurthy Acharya, S. Prasad, N. Venkataramani* and S.N. Shringi \\ Department of Physics, Indian Institute of Technology, Powai, Mumbai 400 076, India \\ * Advanced Center for Research in Electronics, Indian Institute of Technology, Powai, Mumbai 400 076, \\ India
}

\begin{abstract}
Study of M-type hexagonal ferrite films ( $\mathrm{BaFe}_{12} \mathrm{O}_{19}$ and $\mathrm{SrFe}_{12} \mathrm{O}_{19}$ ) is drawing a lot of interest due to their potential applications. Ba ferrite films with perpendicular anisotropy have been studied due to their projected use in perpendicular recording media, magneto-optic recording media and in microwave/millimeter wave devices. The current interest in depositing these films with in plane anisotropy is for use in high density longitudinal recording media. There have been attempts to deposit these materials, mostly on crystalline substrates though without complete control over the orientation. We have for the first time deposited the sputtered strontium ferrite films and could vary the texture of the film to obtain both perpendicular and in plane anisotropy. It was found that the films prepared at lower if power when annealed at temperatures $\geq 800^{\circ} \mathrm{C}$ showed perpendicular anisotropy while the films prepared with higher if power after similar annealing showed in plane anisotropy. These films had been prepared without substrate heating during sputter deposition and the as deposited films were X-ray amorphous and were nonmagnetic. However, these 'as deposited' films when annealed, showed different textures depending on the deposition conditions, as if these deposition conditions leave some signature in the films, which eventually decides the texture of these films. The microstructural studies showed that though the 'as deposited' films were Xray amorphous, oriented microcrystallites form during deposition, which could be controlling the texture at the time of complete crystallization during annealing.
\end{abstract}

\section{INTRODUCTION}

$\mathrm{M}$-type hexagonal ferrites $\left(\mathrm{BaFe}_{12} \mathrm{O}_{19}\right.$ and $\left.\mathrm{SrFe}_{12} \mathrm{O}_{19}\right)$ are known for their high uniaxial magnetocrystalline anisotropy (with the easy axis of magnetization along the hexagonal c-axis) and their chemical stability [1]. They have been used in bulk form for many applications due to their hard magnetic properties, for example, as permanent magnets. The particulates of these ferrites have drawn a substantial interest in recent times, as they were shown to exhibit good recording characteristics for both longitudinal and vertical recording [2-4].

Over the past decade there have been many efforts in developing thin films with perpendicular aniostropy for high density perpendicular recording media [5-6] and thin films of hexagonal ferrites are one of the important candidates along with Co-alloy films. There have been a number of reports on depositing $\mathrm{Ba}$ ferrite $(\mathrm{BaM})$ thin films with $\mathrm{c}$-axis orientation normal to the film plane[7-17]. The high density perpendicular recording characteristics of $\mathrm{Ba}$ ferrite thin film media have also been reported [18-19].

The current interest has been in developing these ferrite films for high density longitudinal recording media [20-24]. For this purpose films with the c-axis lying randomly within the film plane, would be preferable. The films which are used in present high density recording medium are $\mathrm{Co}$-alloy films such as $\mathrm{CoCrTa}, \mathrm{CoCrPt}$ etc. [25]. In comparison to these $\mathrm{Co}$-alloy films, hexagonal ferrite thin films have lower saturation magnetization $\left(M_{s}\right)$ but higher anisotropy field. The higher recording densities need narrower transition width which is proportional to $M_{r} t / H_{c}$, where $M_{r}$ is the remnant magnetization, $t$ is the film thickness and $H_{c}$ is the coercivity. Hexagonal ferrite thin films have higher $H_{c}$ and lower $M_{s}$ in comparison to Co-alloy films [22]. The hexagonal ferrites show good chemical and thermal stability which would result in longer storage life of the media. Since they show good tribological performances the overcoating may not be necessary for these ferrite media resulting in simplified processing and reduced spacing loss [21-24]. In addition the intergranular coupling is very small in case of hexagonal ferrite thin films resulting in better high density recording characteristics [20,24]. Hylton et al [20] have reported $0.5 \mathrm{Gbits} \mathrm{inch}^{2}$ recording on longitudinal $\mathrm{BaM}$ media and suggested that this material is a promising candidate for 10 Gbits/inch ${ }^{2}$ recording.

There has been a large interest in developing hexagonal ferrite thin films for high density Magneto-optical (MO) recording [26-29]. BaM shows large MO effects at in the near UV region associated with Fe ions and the partial substitution of Fe by Co gives increased MO effects at the near IR region [28-29]. The MO effects can be enhanced by incorporating the material into a multilayer structure [29-30]. In addition, there have been attempts in depositing these films for microwave and millimeter wave applications [14,17].

The hexagonal ferrite films have been deposited by a number of techniques such as conventional dc and rf sputtering, targets facing type sputtering, pulsed laser deposition etc. using in-situ heating or post deposition annealing [7-30]. Most of the work on the hexagonal ferrite thin films have concentrated on BaM films. We have recently reported the detailed work on Sr ferrite (SrM) thin films prepared by if diode sputtering [31-34]. Our work has shown that it is possible to alter the texture and the properties of SrM films by changing the deposition and annealing conditions. Using different process parameters it has been possible to get SrM films with both c-axis orientation normal to the film plane and in the film plane. We had earlier reported how deposition and annealing conditions can be used in a simple fashion to control the texture of SrM films[34]. In this paper we present the details of the study carried out on various crystalline and amorphous fused quartz substrates. We demonstrate that the deposition conditions have dominant effect in the control of texture of SrM films irrespective of the substrates used. 


\section{EXPERIMENT}

The films were prepared by if sputtering in a Leybold Z400 system. A 3 inch diameter commercial M-type strontium ferrite disc was used as the target. The sputtering gas was a mixture of argon and oxygen. Oxygen to argon ratio (R) was varied from 0 to $25 \%$. The total gas pressure was $6 \times 10^{-3}$ mbar. The if power (P) was varied from 60 to $330 \mathrm{~W}$. The target to substrate distance was kept at $50 \mathrm{~mm}$. The substrates were neither heated nor water cooled during sputtering. The deposition rates were of the order of $8-12 \AA / \mathrm{min}$. at $\mathrm{P}=60 \mathrm{~W}$ to $35-45 \AA / \mathrm{min}$. at $\mathrm{P}=330 \mathrm{~W}$, depending on the $\mathrm{R}$ values. For annealing, the films were introduced into a hot furnace. The films on $\mathrm{Si}$ substrates were annealed for 3 hours at $800^{\circ} \mathrm{C}$ in air and were furnace cooled, whereas the films on the other substrates were similarly annealed but at $900^{\circ} \mathrm{C}$ for two hours. The crystal structure and the texture of the films were determined using X-ray diffractometry (XRD). The magnetization and $\mathrm{M}-\mathrm{H}$ loops were measured using a vibrating sample magnetometer. The thickness of the films was measured using a profilometer. The films with thicknesses of the order of $2000 \AA$ were used in this study. The composition of the films were studied using inductively coupled plasma analysis and energy dispersive $\mathrm{X}$-ray analysis.

\section{FILMS DEPOSITED ON Si(100) and Si (111) SUBSTRATES}

\subsection{The effect of $r$ power}

In Fig. 1(a), we have shown the XRD patterns of the annealed films deposited on $\mathrm{Si}(100)$ substrates with $\mathrm{P}=60 \mathrm{~W}, 230 \mathrm{~W}$ and $330 \mathrm{~W}$, all with $R=15 \%$. We may recall here that the 'as deposited' films and those annealed at temperatures $<800^{\circ} \mathrm{C}$ were $\mathrm{X}$-ray amorphous [3]34]. When annealed at temperatures $\geq 800^{\circ} \mathrm{C}$ all the films show $\operatorname{SrM} X R D$ peaks. The films with $\mathrm{P}=60 \mathrm{~W}$ show prominent $(000)$ peaks indicating $c$-axis orientation normal to the film plane. The films with $P=230 \mathrm{~W}$ show random orientation. The films with $\mathrm{P}=330 \mathrm{~W}$ on the other hand, show prominent $(110)$ and $(220)$ peaks indicating $c$-axis in plane orientation. Hence, by changing the rf power during the deposition one can vary the texture of the films from $\mathrm{c}$ - axis normal to random orientation, and then to c-axis in plane orientation.

In Table 1, we have listed different magnetic parameters of the films deposited on $\mathrm{Si}(100)$ and $\mathrm{Si}(111)$ substrates under different deposition conditions and annealed at $800^{\circ} \mathrm{C}$. The films with $\mathrm{P}=60 \mathrm{~W}$ have $\left(\mathrm{M}_{\Gamma} / \mathrm{M}_{\mathrm{s}}\right)_{\perp}$ values $\approx 1$, showing that these films have their magnetic easy axis normal to the film plane. (This can be seen from the rectangular perpendicular $\mathrm{M}-\mathrm{H}$ loop shown for one of the films with $P=60 \mathrm{~W}$ in Fig. $\mathrm{l}(\mathrm{b})$ ). On the other hand, the films with $\mathrm{P}=230 \mathrm{~W}$ have their hard axis normal to the film plane with the easy axis lying randomly within the film plane. As mentioned earlier, such films are of particular interest for longitudinal recording media applications. Like if power, oxygen to argon ratio during the sputtering also has some effect on the properties of the films as can be noted from Table 1 [34]. For example, for a particular value of if power, $H_{c}$ decreases with increase in the oxygen to argon ratio.

$\mathrm{Cu} \mathrm{K}$.

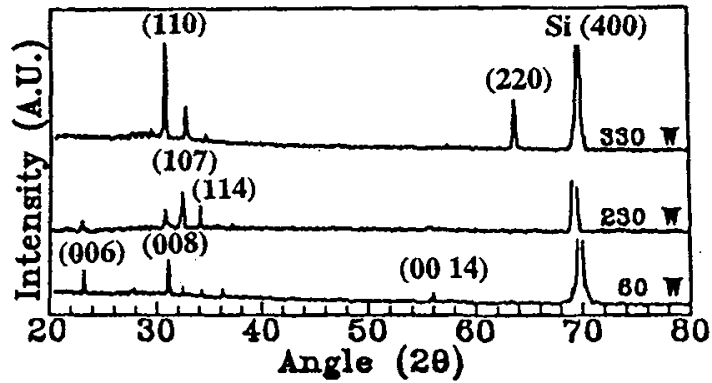

(a)

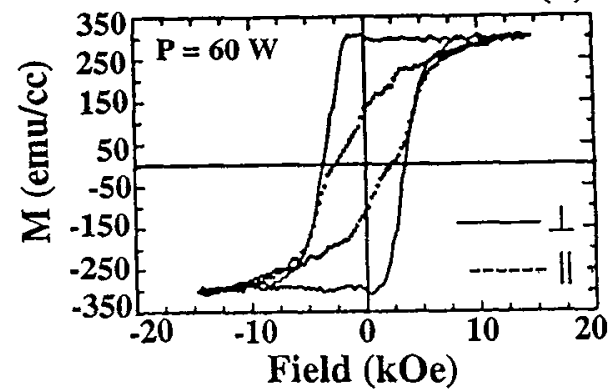

Fig.1(a) The X-ray diffraction patterns of annealed strontium ferrite films deposited on $\mathrm{Si}(100)$ substrates at different if powers for $R=15 \%$, and (b) Perpendicular ( 1 ) and in plane (II) $M-H$ loops for the film with $P=60 \mathrm{~W}$ and $R=15 \%$.

Table 1. The magnetic parameters of strontium ferrite films deposited on Si substrates under different deposition conditions and annealed at $800^{\circ} \mathrm{C}$ (The films with $\mathrm{P}=330 \mathrm{~W}$ and $\mathrm{R}=0 \%$ did not saturate upto $15 \mathrm{kOe}$ )

\begin{tabular}{|c|c|c|c|c|c|c|c|}
\hline Power $(\mathrm{W})$ & $\mathrm{O}_{2} / \mathrm{Ar}$ ratio $(\%)$ & $\mathrm{Substrate}$ & $\mathrm{M}_{\mathrm{s}}(\mathrm{emu} / \mathrm{cc})$ & $\left(\mathrm{H}_{\mathrm{c}}\right)_{\perp}(\mathrm{Oe})$ & $\left(\mathrm{H}_{\mathrm{v}}\right)_{\|}(\mathrm{Oe})$ & $\left(\mathrm{M}_{\mathrm{r}} / \mathrm{M}_{s}\right)_{\perp}$ & $\left(\mathrm{M}_{\mathrm{v}} / \mathrm{M}_{\mathrm{s}}\right)_{\mathrm{L}}$ \\
\hline 330 & 1.5 & $\mathrm{Si}(100)$ & 328 & 4100 & 3930 & 0.53 & 0.59 \\
& & $\mathrm{Si}(111)$ & 334 & 3930 & 3930 & 0.56 & 0.60 \\
\hline & 15 & $\mathrm{Si}(100)$ & 309 & 3300 & 3210 & 0.64 & 0.70 \\
& & $\mathrm{Si}(111)$ & 322 & 3930 & 3930 & 0.65 & 0.68 \\
\hline & 25 & $\mathrm{Si}(100)$ & 321 & 2860 & 3035 & 0.68 & 0.52 \\
& & $\mathrm{Si}(111)$ & 326 & 3030 & 3210 & 0.65 & 0.54 \\
\hline 60 & 0 & $\mathrm{Si}(100)$ & 319 & 4820 & 4820 & 0.91 & 0.58 \\
& & $\mathrm{Si}(111)$ & 304 & 4820 & 4820 & 0.93 & 0.61 \\
\hline & 1.5 & $\mathrm{Si}(100)$ & 318 & 4290 & 3930 & 1.00 & 0.47 \\
& & $\mathrm{Si}(111)$ & 301 & 4030 & 3930 & 1.00 & 0.45 \\
\hline & 15 & $\mathrm{Si}(100)$ & 328 & 3390 & 3220 & 1.00 & 0.36 \\
& & $\mathrm{Si}(111)$ & 338 & 3390 & 3180 & 1.00 & 0.38 \\
\hline & 25 & $\mathrm{Si}(100)$ & 298 & 3210 & 3030 & 1.00 & 0.45 \\
& & $\mathrm{Si}(111)$ & 328 & 3210 & 3040 & 1.00 & 0.46 \\
\hline
\end{tabular}




\subsection{The effect of substrate orientation}

One of the interesting points that is quite clear from Table 1 is that the films deposited under similar conditions but on differently oriented silicon substrates, $\mathrm{Si}(100)$ and $\mathrm{Si}(111)$, show similar magnetic parameters which are within $\pm 5 \%$. This shows, that the texture and properties of the films are determined by the deposition conditions.

\section{FILMS DEPOSITED ON SAPPHIRE(110) SUBSTRATES}

In case of the films deposited on Sapphire (110), the effect of of power on the texture of the films was largely similar to the films on Si substrates except that, in the case of the films on sapphire substrates, for $\mathrm{P}=330 \mathrm{~W}$ no in plane orientation was observed. It is interesting to note here that in the case of the films deposited on sapphire substrates, very high values of coercivities (8-9.5 kOe) were obtained due to Al diffusion from the substrates as was also reported by Hylton et al [35]. For example, in Fig. 2(a) the M-H loops for a film with perpendicular anisotropy have been shown where the $H_{c}$ is the order of $9 \mathrm{kOe}$. The effect of diffusion from the substrate to the film can be seen from the XRD patterns of the 'as deposited' films and those annealed at different temperatures shown in the Fig. 2 (b). The Sapphire $(10)$ and $(220)$ peaks are clearly seen in the 'as deposited' films. As the annealing temperature is increased the relative intensities of these peaks decrease and at an annealing temperature of $1000^{\circ} \mathrm{C}$, the sapphire peaks disappear completely. This indicates that the film substrate interface is not sharp at higher annealing temperatures due to diffusion of Al from the substrate to the film. It is also known that Al substitution in hexagonal ferrites increases the coercivity of these ferrites and these ferrites with very high coercivities are useful for microwave applications [36].

(a)
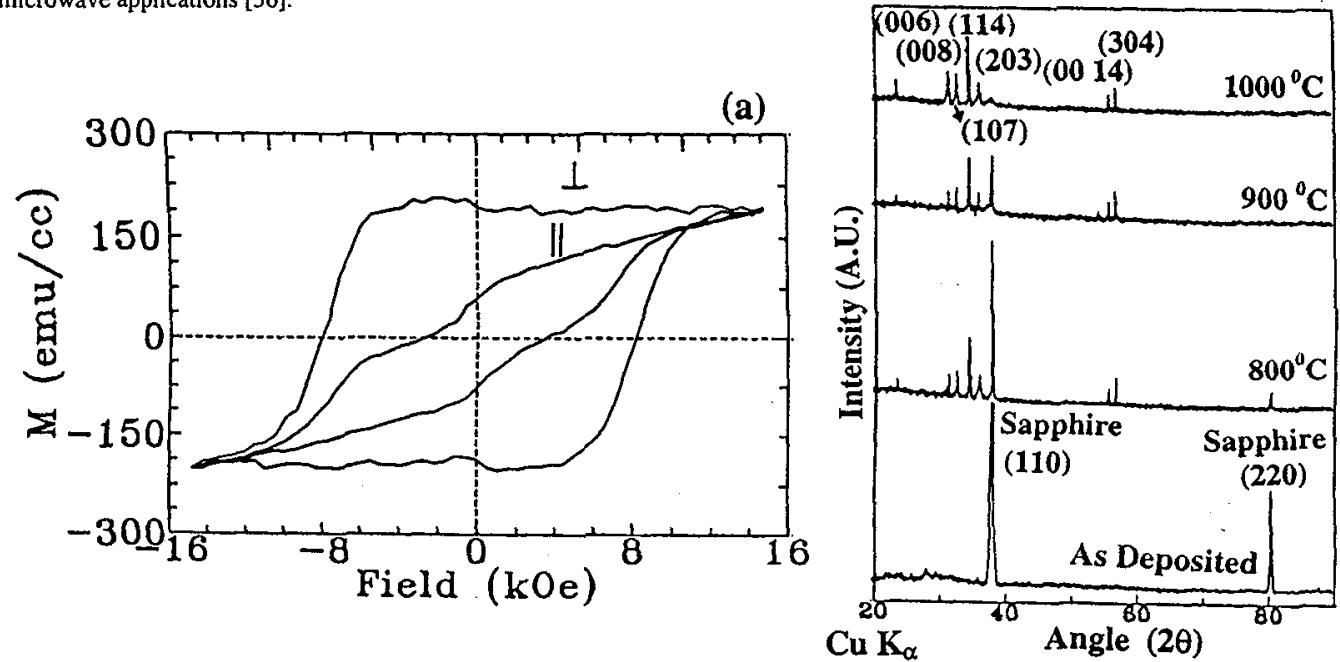

(b)

Fig. 2 (a) The Perpendicular ( $L$ ) and in plane (ii) M-H loops for a strontium ferrite film with $P=60 \mathrm{~W}$ and $\mathrm{R}=15 \%$ on sapphire(110) annealed at $900^{\circ} \mathrm{C}$, and (b) the XRD patterns of the films with $\mathrm{P}=230 \mathrm{~W}$ and $\mathrm{R}=1.5 \%$.

\section{FILMS ON AMORPHOUS SUBSTRATES}

From the above discussions it is clear that the orientation of the films is determined mainly by deposition parameters. The effects of substrate orientation is minimal. Hence it would be interesting to know if the same effects are prevalent on an amorphous substrate such as fused quartz. These substrates are relatively inexpensive and due to their high crystallization temperatures, the films deposited on them can be annealed at higher temperatures.

In Table 2 we list a few parameters such as magnetization, coercivity, remanance values etc. for the films deposited at $P=60 \mathrm{~W}$ and 330 $\mathrm{W}$ on fused quartz and $\mathrm{Si}(100)$ substrates. Here the $\mathrm{c}$-axis orientation parameter $\mathrm{f}_{\mathrm{c}}(001)$ is determined by $\mathrm{X}$-ray diffraction and is defined as $f_{c}(001)=\left(P-P_{0}\right) /\left(1-P_{0}\right)$ with $P=\sum I(00 l) / \Sigma I(h k l)$ where $l(h k l)$ is the intensity of (hkl) peaks for the specimen film and $P_{0}=$ $\sum \mathrm{I}_{0}(00) / \sum \mathrm{I}_{0}(\mathrm{hkl})$ where $\mathrm{I}_{0}(\mathrm{hkl})$ is the intensity of $(\mathrm{hkl})$ peaks for a $\mathrm{SrM}$ powder diffraction pattern $[34]$. $\mathrm{f}_{\mathrm{c}}(001)$ will be 1 for the film with complete 00 ) orientation and 0 for the films with complete random orientation. Similarly $f_{c}(110)$ is also calculated for evaluating (110) orientation of the films.

Table 2. The orientation and magnetic parameters of strontium ferrite thin films made on $\mathrm{Si}(100)$ and fused quartz substrates.

\begin{tabular}{|c|c|c|c|c|c|c|c|c|c|}
\hline Substrate & Power $(\mathrm{W})$ & $\mathrm{O}_{2} / \mathrm{Ar}$ ratio & $\mathrm{f}_{\mathrm{c}}(001)$ & $\mathrm{f}_{\mathrm{c}}(110)$ & $\mathrm{M}_{\mathrm{s}}(\mathrm{emu} / \mathrm{cc})$ & $\left(\mathrm{H}_{\mathrm{c}}\right)_{1}(\mathrm{Oe})$ & $\left(\mathrm{H}_{\mathrm{c}}\right)_{\mathrm{H}}(\mathrm{Oe})$ & $\left(\mathrm{M}_{\mathrm{v}} / \mathrm{M}_{\mathrm{s}}\right)_{\perp}$ & $\left(\mathrm{M}_{\mathrm{r}} / \mathrm{M}_{s}\right)$ \\
\hline Si(100) & 60 & 15 & 0.95 & 0 & 328 & 3390 & 3220 & 1.00 & 0.36 \\
F. Quartz & 60 & 15 & 0.95 & 0 & 290 & 5150 & 4540 & 1.00 & 0.41 \\
\hline Si(100) & 330 & 15 & 0 & 0.84 & 309 & 3300 & 3210 & 0.64 & 0.70 \\
F. Quartz & 330 & 15 & 0 & 0.78 & 280 & 4130 & 4130 & 0.59 & 0.65 \\
\hline
\end{tabular}


The films with $P=60 \mathrm{~W}$ show similar values of $\mathrm{f}_{c}(001)$ and $\left(\mathrm{M}_{\mathrm{r}} / \mathrm{M}_{\mathrm{s}}\right)_{\perp}$ indicating that the films on amorphous fused quartz substrates also have $c$-axis orientation normal to the film plane. Similarly the films with $P=330 \mathrm{~W}$ on fused quartz substrates also showed $c$-axis in plane orientation. The coercivity values of the films on Si substrates were smaller than those on fused quartz substrates. The above results are significant considering the interest in using amorphous substrates for recording media. [ 25,37]. We would also like to emphasise the fact that no seeding layers were necessary to get the textured growth, unlike in the case Co-alloy media on amorphous substrates [ 25,37 ]. As discussed in sections 3-5, the 'as deposited' SrM films were X-ray amorphous and nonmagnetic. These 'as deposited' films when annealed, showed different textures depending on the deposition conditions as if the deposition conditions leave some signatures which eventually decide the texture. This feature was explored by us using microstructural studies of 'as deposited' films using transmission electron microscopy. These studies revealed that the 'as deposited' films were made up of case specific microcrystallites, which could be responsible for the observed textured growth of the films, when annealed at higher temperatures [38].

\section{CONCLUSIONS}

The texture of the sputtered strontium ferrite films vary from c-axis perpendicular to random orientation and then to c-axis in plane orientation depending on the deposition conditions. The textured growth of these films could be made on crystalline substrates such as $\mathrm{Si}(100), \mathrm{Si}(111)$, sapphire(110) and also on amorphous fused quartz substrates. The films on sapphire substrates showed very high coercivities due to Al diffusion into the film. These results are significant due to the application potential of these textured films.

\section{Acknowledgments}

One of the authors (B.R.A.) acknowledges the Council of Scientific and Industrial Research, New Delhi, for the financial support. A part of the work was carried out under contract from Indo French Center for the Promotion of Advanced Research (Centre Franco Indien pour la Promotion de la Recherce Avancee ), New Delhi.

\section{References}

[1] Smith J., Wijn H.P.J., Ferrites (John Wiley, New York, 1959).

[2] Speliotis D.E., IEEE Trans. Magn., 25 (1989) 4048-4051.

[3] Simmons R.G., IEEE Trans. Magn., 25 (1989) $4051-4053$.

[4] Fuziwara T., IEEE Trans. Magn., 21 (1985) 1480-1485.

[5] Yamamato S., Nakamura Y., Iwasaki S., IEEE Trans. Magn., 23 (1987) 2070.

[6] Honda S., Ouchi K., Iwasaki S., J. Appl. Phys., 75 (1994) 5484.

[7] Naoe M., Hasunuma S., Hoshi Y,, Yamanaka S., IEEE Trans. Magn., 17 (1981) 3184.

[8] Matsuoka M., Hoshi Y., Naoe M., Yamanaka S., IEEE Trans. Magn., 18 (1982) 1119

[9] Matsuoka M., Hoshi Y., Naoe M., Yamanaka S., IEEE Trans. Magn., 21 (1984) 800.

[10] Morisako A., Matsumoto M., Naoe M., Electron. Commun. Jpn., 70 (1987) 55.

[11] Morisako A., Matsumoto M., Naoe M., IEEE Trans. Magn., 23 (1987) 56.

[12] Morisako A., Matsumoto M., Naoe M., IEEE Trans. Magn., 24 (1988) 3024.

[13] Matsushita N., Noma K., Naoe M, IEEE Trans. Magn., 30 (1994) 4053.

[14] Yuan M.S., Glass H.L., Adkins L.R., Appl. Phys. Lett., 53 (1988) 340.

[15] Sui X., Kryder M.H., Wong B.Y., Laughlin D.E., IEEE Trans. Magn., 29 (1993) 3751.

[16] Sin K., Sivertsen M., Judy J.H., J. Appl. Phys., 75 (1994) 5972.

[17] Carosella C.A., Chrisey D.B., Lubitz P., Horwitz J.S., J. Appl. Phys., 71 (1992) 5107.

[18] Matsuoka M., Naoe M., J. Appl. Phys., 57 (1985) 4040.

[19] Morisako M., Matsumoto M., Naoe M., IEEE Trans. Magn., 22 (1986) 1146.

[20] Hylton T.L., Parker M, Ullah M., Coffey K.R., Umphress R., Howard J.K., J. Appl. Phys., 75 (1994) 5960.

[21] Sui X., Kryder M.H., Appl. Phys. Lett., 63 (1993) 1582.

[22] Sui X., Kryder M.H., IEEE Trans. Magn., 30 (1994) 4044.

[23] Rosenblum S.S., Hayashi H., Li J., Sinclair R., IEEE Trans. Magn., 30 (1994) 4047.

[24] Li J., Rosenblum S.S., Nojima W., Hayashi H., Sinclair R., IEEE Trans. Magn, 31 (1995) 1749.

[25] Laughlin D.E., Cheong B., Feng Y.C., Lambeth D.N., Scripta Metallurgica et Materialia, 33 (1995) 1525.

[26] Nakamura H., Ohmi F., Kaneko Y., Sawada Y., Watada A., Machida H., J. Appl. Phys., 61 (1987) 3346.

[27] Carey R., Sandoval P.A. G-., Newman D.M., Thomas B.W.J., IEEE Trans. Magn., 29 (1993) 3799.

[28] Papakonstantinou P., Atkinson R., Salter I.W., Gerber R., J.Magn. Soc. Jpn., S1 (1995) 177.

[29] Atkinson R., Salter I.W., Xu J, Appl.Opt., 31 (1992) 4847.

[30] Naoe M., Nakagawa S., IEEE Trans. Magn., 29 (1993) 3393.

[31] Acharya B.R., Venkataramani N., Prasad S., Shringi S.N., Krishnan R.,Tessier M., Dumond E., IEEE Trans. Magn., 29 (1993) 3370 .

[32] Acharya B.R., Krishnan R., Prasad S., Venkataramani N., Ajan A., Shringi S.N., Appl. Phys. Lett, 64 (1994) 1579.

[33] Acharya B.R., Piramanayagam S.N., Ajan A., Shringi S.N., Prasad S., Venkataramani N., Krishnan R., Kulkarni S.D., Date S.K., J. Magn. Magn. Mater. , 140-144 (1995) 723.

[34] Acharya B.R., Prasad S., Venkataramani N., Shringi S.N., Krishnan R., J. Appl. Phys., 79 (1996) 478.

[35] Hylton T.L., Parker M.A., Howard J.K., Appl. Phys. Lett., 61 (1992) 867.

[36] Nicolas J., "Microwave ferrites", Ferromagnetic Materials, Wolfarth E.P., Ed. (North-Holland, Amsterdam, 1980) pp. $291-292$.

[37] Rouch G.C., Liu J.J., Lu S., Borzoneyeni I., Gao C., Gui J., presented at INTERMAG ‘96, Seattle, April 1996.

[38] Acharya B.R., Sundararaman M., Prasad S., Venkataramani N., Shringi S.N., Krishnan R. (to be published in IEEE Trans. Magn.) 